\title{
OUR SOLAR SYSTEM LAST WEEK
}

Over the past few days, Earthlings have been treated to some stunning images from across the Solar System. Jupiter and Mars were snapped by spacecraft on their way to more distant destinations, the gap between Earth and the Sun was captured by the STEREO mission, and the Cassini spacecraft collated months of hard work to give us fresh views of Saturn and its moon Titan.

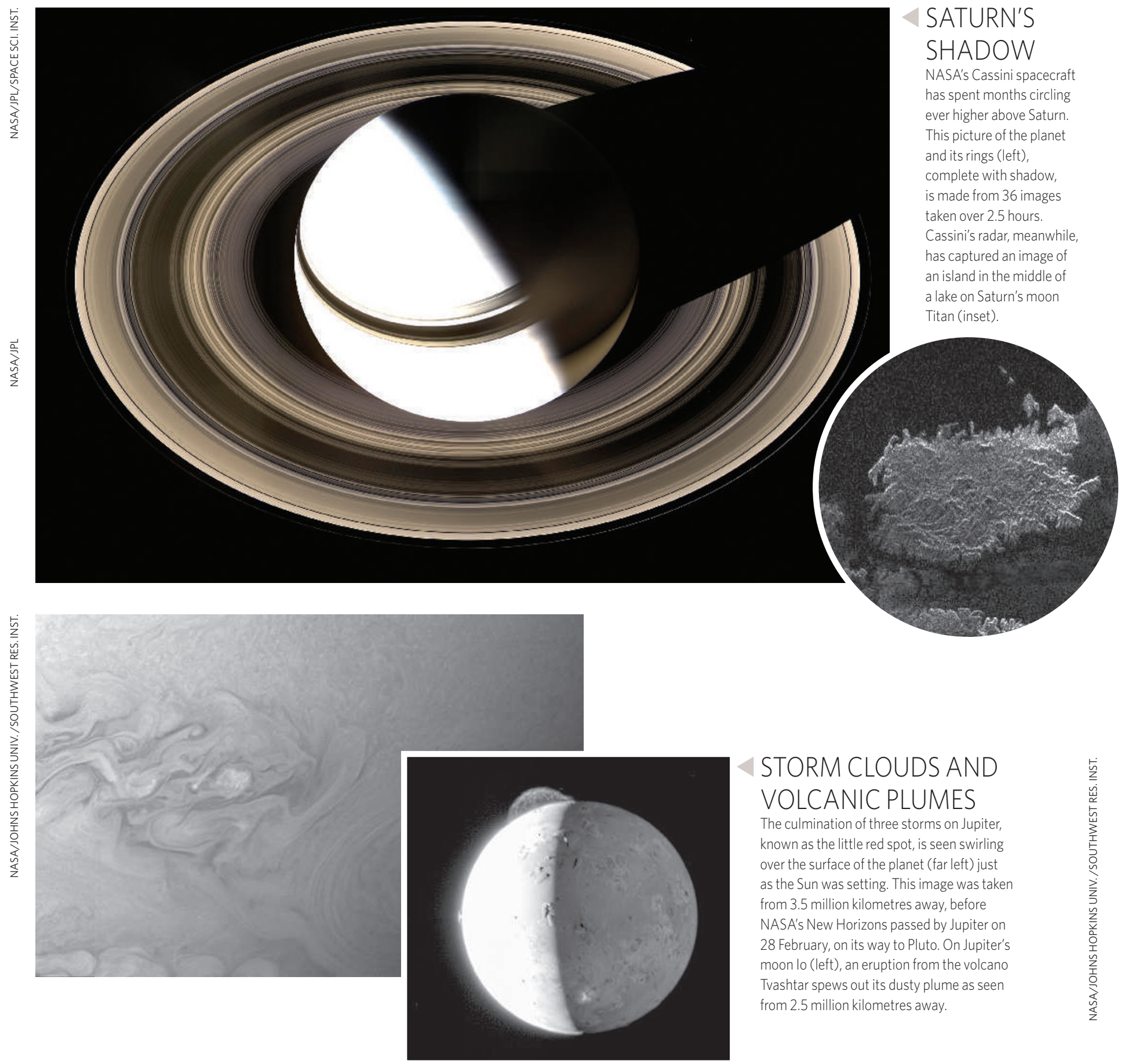




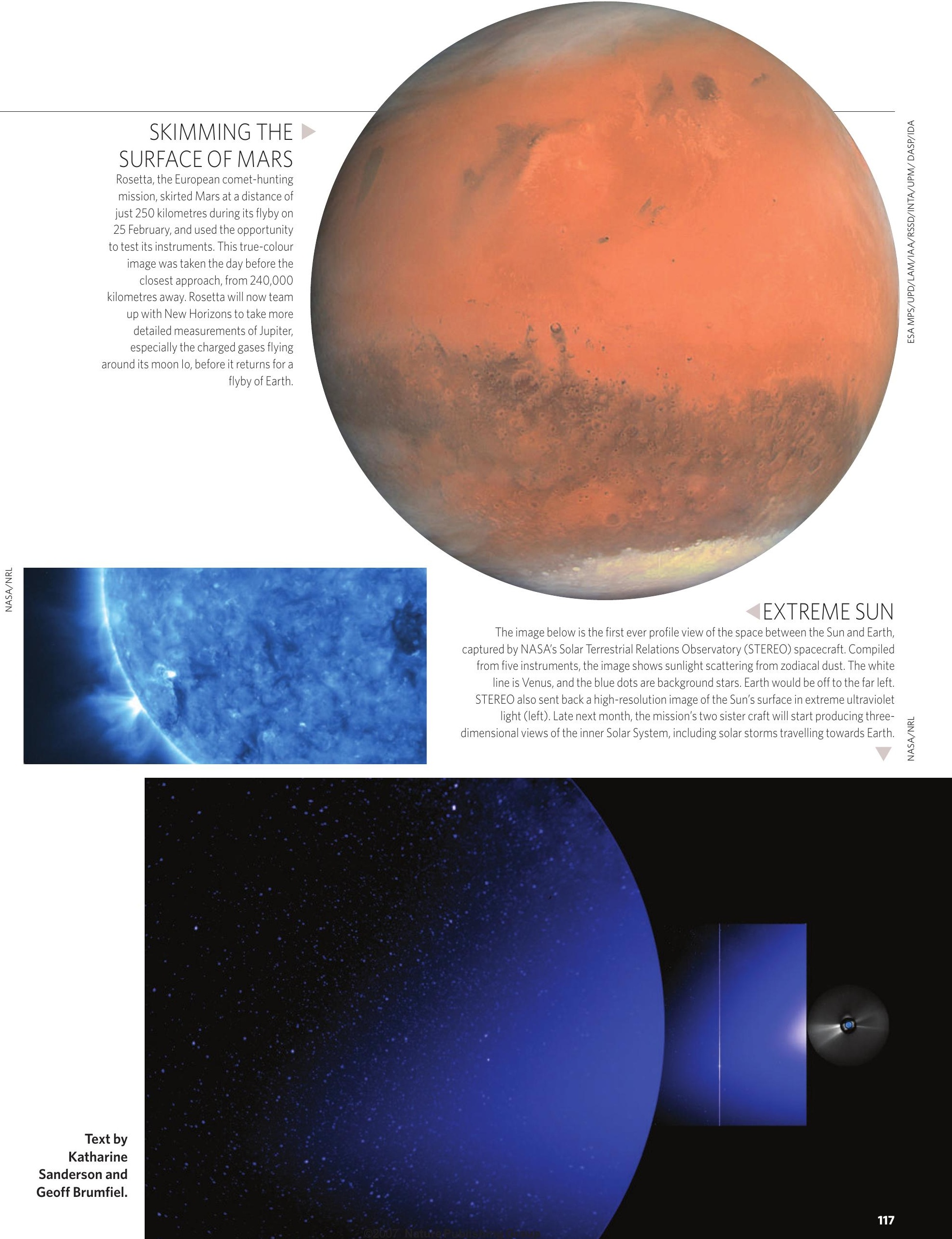

